\title{
ethic@ \\ THE DUALISM OF PRACTICAL REASON: THE PROFOUNDEST PROBLEM OF ETHICS REVISITED
}

\author{
CINARA NAHRA ${ }^{1}$
}

(UFRN/Brasil)

\begin{abstract}
The aim of this article is to discuss and revisit what Sidgwick called the profoundest problem of ethics: the dualism of practical reason. I argue that Crisp's dual source view provides a good solution for the dualism via the small cost principle showing that we have to balance agent relative and agent neutral reason in a kind of a rational "negotiation" between our egoistic and our altruistic motivations. I suggest, however, that in order to justify his solution it is necessary to go beyond Sidgwick establishing a limit for the acceptance of egoism as a legitimate method of ethics. I argue that the pure egoism is a threat to reason and civilization and in order to show this I put forward two arguments: a Kantian logic argument and a utilitarianist argument. I propose then that the dualism is not only the profoundest problem of ethics, but also one of the more serious; it is the biggest contemporary ethical puzzle of humankind, and whose practical solution is of paramount importance for the future of life on earth.
\end{abstract}

Keywords: Dualism of practical reason; Dual source view; Altruism; Egoism

"Get knowledge, get riches, but with all thy getting get understanding" Inscription at the old administrative building of St Anne's College, University of Oxford

When Sidgwick in 1874 first expressed the conflict between "me" and "the others" he said that this was the profoundest problem of ethics and named this the dualism of practical reason $^{2}$. Generations of philosophers dig on it $^{3}$, as he left the solution of the problem for future generations. Since then we have been trying to decipher exactly what is dualism, since Sidgwick himself seems to have left for us some possible options of his own in the seven editions of the Methods of Ethics in which he developed and evolved his idea. The dualism of practical reason can be described as the conflict between self-interest and altruism, interest and duty, my happiness and general happiness, self-interest and duty ${ }^{4}$, the conflict between psychological hedonism and ethical hedonism ${ }^{5}$, or between egoistic hedonism and universalistic hedonism. ${ }^{6}$ But it is primarily a conflict about reasons, as Sidgwick himself admits rejecting Butler's expression Dualism of the Governing Faculty and establishing Dualism of Practical Reason (a 
view that he confesses came to his mind while struggling to assimilate Kant and Mill) since what is at stake is the authority of reason ${ }^{7}$.

The dualism of practical reason is above all related to the fact that we have reasons to pursue our own interests, or in other words, our happiness, but we also have reasons to pursue the general interest and the general happiness. As Phillips ${ }^{8}$ wrote, Sidgwick shows that we have genuine agent-relative reasons and genuine agent-neutral reasons. The problem described by Sidgwick, is that sometimes these two kinds of reasons conflict in some practical decisions. A decision has to be made, and if I have reasons to do what fosters my well-being (action $a$ ) and what fosters the general well-being (action $b$ ), where must I practice [ $a$ and $\mathrm{b}$ ], but $a$ and $b$ conflict (if you practice $a$ this implies no $b$ and if you practice $b$ this implies no $a$ ) then I clearly face a practical contradiction since [no $(a$ and $b)$ ] even though I must practise $[a$ and $b]$. If this is so, the despair that Sidgwick arrived to at the end of his Methods, contemplating the possibility of the cosmos of duty being transformed into chaos is totally comprehensible. As Sidgwick says (9566):

But in the rarer cases of a recognised conflict between self-interest and duty, practical reason, being divided against itself, would cease to be a motive on either side; the conflict would have to be decided by the comparative preponderance of one or other of two groups of non-rational impulses. If then the reconciliation of duty and self-interest is to be regarded as a hypothesis logically necessary to avoid a fundamental contradiction in one chief department of our thought, it remains to ask how far this necessity constitutes a sufficient reason for accepting this hypothesis ${ }^{9}$.

We can take Sidgwick as suggesting that if we don't solve this contradiction morality is jeopardised and we should abandon the idea of rationalising it entirely. What Sidgwick is saying arrives to us as a kind of conclusion: if reason can not solve the contradiction, then we should admit that the contradiction is solved by emotions, not reasons. If reason itself cannot solve the conflict then emotion takes the lead in this process. If we are not prepared to accept this result then we have to give a rational account of the solution to the contradiction, a task that Sidgwick left to us, the so-called philosophers of the future.

Many philosophers took this task seriously, but I believe that the most successful answer came from Roger Crisp and his dual source view. Crisp wrote that he was developing a version of Sidgwick's dualism of practical reason ${ }^{10}$, but he has been doing more than this, he has been also working on a solution for the problem. Crisp recognises that Sidgwick may have rejected his solution as a version of aesthetic intuitionism ${ }^{11}$ but the point I want to make here is that the dual source view is a partial solution for the problem remaining, and could be the perfect solution if Crisp ventures beyond Sidgwick to solve the problem that Sidgwick raised. 
Crisp stablishes the scope of his project examining the prospect for a view which steers between the extremes of moralism and egoism following the Aristotelian strategy of looking for the truth in different positions, incorporating elements of both universalism and egoism ${ }^{12}$. Crisp proposes:

\begin{abstract}
Why did Sidgwick not consider a version of the dualism which, in cases of conflict, weighs the strength of each reason against the other? So, for example, I might conclude in one case that I have strongest reason to promote the overall good at some small cost to myself, and in another that I have strongest reason to promote my own good to a large degree at some small cost to the overall good. This position, according to which we have both egoistic and utilitarian pro tanto reasons for action, strikes me as very plausible ${ }^{13}$.
\end{abstract}

The best way to see how this would work is to analyse the series of "doors examples" that Crisp gives in Reasons and the Good. In the door case $1^{14}$, faced with two magic doors A and B, we have three options: the first option is not to go through any of the doors (in this case you will suffer an extremely painful shock). The second option is to pass through door A (nothing will happen to you and to anyone else) and the third option is to walk through door B (nothing would happen to you but a stranger will suffer an extremely painful shock and once you have walked through the chosen door you will forget everything). Crisp argues that if you are an egoist you would obviously choose one of the doors, as otherwise you would suffer a painful shock, but it would be indifferent for you going through door A and B as the choice you make will not affect your own welfare anymore. Therefore, if you are an egoist you could easily choose to pass through door B causing someone else extreme pain.

Crisp's conclusion is that egoism is mistaken, as the welfare of others gives you a reason to refrain from choosing door $\mathrm{B}$, a reason that is not egoistic anymore but derives from the universal point of view. Crisp seems to be saying here that it is obvious that we have egoistic reasons to pass through one of the doors (otherwise you will be in excruciating pain) but you also have reasons to choose door A over B, to avoid someone else suffering and these reasons are not egoistic anymore, they are agent-neutral reasons. Crisp suggests that what we do in these cases is precisely what the dual source view predicts: we weight up reasons, egoistic and universal reasons. Crisp then proposes the door case $2^{15}$ where like door case 1 if you don't pass through any of the magic doors you will suffer a painful electric shock. Now, if you pass through door A you will experiment an almost imperceptible shock, but if you pass through door B you will not suffer the almost imperceptible shock anymore, but a stranger will suffer a painful shock. Crisp argues that here, as in door case 1, you obviously still have strong reasons to walk through one of the doors ( to avoid the painful shock for yourself) and you still have 
reasons, agent neutral reasons, to choose door A over B even though going through door A you experiment some discomfort. Crisp seems to be suggesting that if you are a pure egoist you would have chosen door B and you would have reasons for this, agent- relative reasons, but what people actually do is to weight up the egoistic against the universal reasons and when this happens the balance in this case is still on the side of the universal reasons, and still on the side of choosing door A over door B, as the sacrifice of your wellbeing in this case is at a minimum and by sacrificing your own well-being you avoid an excruciating pain for a fellow human being.

Finally, in the doors case 3 the situation is the same except that if you choose door A you will still receive a significant shock. The shock will be less intense than if you hadn't gone through the door but still painful, and if you choose door B you will not receive the shock but a stranger will instead received a shock of the same intensity, like the one you would have received if you had chosen door A. In this case Crisp seems to be arguing that from the point of view of the universe it is indifferent if you choose door A or B, because the intensity of pain created is the same, although from your point of view it is not obviously indifferent, because the pain generated in choosing door B is your pain and you therefore have genuine egoistic reasons to try to avoid this pain and promote your own well-being, thus choosing B over A, contrarily to the two previous cases. Crisp states ${ }^{16}$ that what is true of Two Doors 3 is that your reason to enter door A is weaker than your reason to enter door B. Here I took Crisp as saying that he doesn't mean that it is irrational to choose A nor that it is not commendable, but meaning that when we weight up the reasons we see that it makes more sense to choose B (egoistic reasons/agent relative reasons) over A (impartial reasons/ agent neutral reasons) in magic doors case 3 than to choose B (egoistic reasons/ no cost to you) over A (impartial reasons/cost to others) in case 1 and even to choose B (egoistic reasons/small cost to you ) over A (impartial reasons/great cost to others ) in magic doors case 2 .

Through the doors and through the dual source view we have not only a different way to put the problem, but we have a solution, or at least, a partial solution for Sidgwick's problem. The conflict between agent-relative reasons and agent- neutral reason, between my own interests and the interests of others, between egoism and altruism is not being solved by emotions anymore, as Sidgwick feared, it is being solved by reason itself, in a kind of "negotiation" between agent relative and agent neutral reasons, a compromise between egoism and altruism. In this interaction a new principle emerges, the one Crisps calls ${ }^{17}$ the small cost principle: whenever you can greatly promote the well-being of another at small cost to yourself, then you have reason to do so. In all the 3 doors cases this is the principle that is doing the 
work. It is not our emotions that are deciding what to do, it is our reason, calculating the costs and the benefits of the different courses of action for ourselves and for others, from our point of view and from the point of view of the universe. This process could become a battle, when the different points of view suggest opposite outcomes, but still reason will have the last say guided now by this new principle that results precisely from this battle field in the form of a compromise between the two commandments of the same reason, that through the small cost principle it is capable of accommodating them.

One problem that remains after establishing the small cost principle is how small is "the small cost to yourself", meaning, how much is each one of us willing to sacrifice in order to promote the welfare of others? There is no universal answer for this, as the threshold could vary for each person based on personal circumstances, culture, education and numerous factors, even emotions, like Sidgwick feared, but the key factor here is still reason and its capacity to control and manage emotions, and reason's role in determining how much weight you give to personal reasons and how much weight you give to universal reasons. Personally, I would say that the more weight you give to universal reasons the more you are on the side of altruism, and the more weight you give to personal reasons the more you are on the side of egoism. An example of a pure egoist would be someone who doesn't give any weight at all to universal reasons and even without any benefit to himself chooses to harm others (as for example someone that in doors case 1 chooses door B even not benefiting from their choice, and in so doing brings a painful electric shock to a stranger). It is clear that the person in this case lacks the capacity to apply universal reasons (derived either from utilitarianism or intuitionism in Sidgwick terminology) and it is clear that there is something morally very wrong with someone who does this. It is more difficult to see what is wrong when a person is weighting up the reasons and avoiding harm to himself as a result of the calculation. Most of us in doors case 2 would use universal reasons derived from utilitarianism, for example, to conclude that we should be willing to receive an almost imperceptible shock in order to avoid a very painful shock to a third person (stranger), but insofar as you increase the intensity of the shock the moral matters become more grey. Where actually is the exact point where things turn around and the personal reasons become stronger and more morally acceptable? It is impossible to determine this point, but this doesn't make the clear cases less clear. Even if you can't universally determine what are the things that greatly promote the well-being of another at a small cost to yourself, as the small costs principle requires, we know through the experience accumulated in the History of humanity that ceteris paribus an imperceptible electric shock counts as a "small cost" when compared to an extremely painful one. Universally speaking, 
humankind learned that suffering is bad, and in this as in many cases the requirements of utilitarianism and deontology/ intuitionism are on the same side, the side of universal reasons.

The pure egoism problem and the threat to reason and civilization

There are, however, remaining problems with the dualism of practical reason that the dual source view doesn't solve. Imagine a extremely selfish person, someone who in doors case 1 and 2 , for example, chooses the option B, i.e. someone who gives weight 0 to universal reasons and decides to bring extreme pain to a stranger, a pain that could easily be avoided by a very small sacrifice to his own well-being (case 2) or even without any sacrifice at all to himself (case 1). In this case Sidgwick would probably still say that this person would have egoistic reasons to do this, and these reasons couldn't be easily dismissed, as they derive from the very fact that "we are concerned with the quality of our existence as an individual in a fundamentally important sense in which we are not concerned with the quality of the existence of other individuals" 18 . We could say that in case 1 the decision is not related with his own well being and so has nothing to do with dualism anymore, being a pathological or even a criminal case, but we could still ask if it is possible for people to simply ignore universal reasons, putting egoism at stake in this case as well. This brings up the question of how far can we go with the special concern that we have with our own existence. The dual source view proposed by Crisp gives a good answer to this question, proposing the weight of reasons, that would work at least as a tie-breaker, putting a limit on egoism, but my worry now would be that the pure egoist would still be able to say that even minimal increases of his own welfare are more important than any benevolent or universal considerations, and in Sidgwick's account this would still be considered rational. But can we go so far with this special concern for ourselves to the point that we could even totally disregard universal reasons? How can we rationally deal with someone who thinks that it is irrational for him to sacrifice even the slightest part of his happiness or well-being for universal ends? As Sidgwick said ${ }^{19}$ the only way of arguing him into aiming at everyone's happiness is to show that this gives him his own best chance of greatest happiness for himself. But since the complete harmony between duty and self-interest cannot be shown, as Sidgwick himself recognises, how can we debunk pure egoism and prove that the pure egoist attitude is wrong?

At this point I propose that in order to answer the profoundest problem of ethics that Sidgwick pointed to, we have to dig around beyond Sidgwick (and probably contrarily to what he thought ) in order to show that pure egoism is not rational anymore and the special concern 
that we have with our own existence that gives us a very good reason to pursue our own welfare cannot allow that 'anything goes' in order to promote it. In order to show this, I will give a Kantian and a utilitarianist argument.

\section{A Kantian logical argument:}

According to Kant there is a fundamental distinction between practical reason and pure practical reason. Practical reason has good and evil as objects while pure practical reason has good as the only object ${ }^{20}$. In practical terms this means that reason in itself doesn't necessarily produce the good, as we can see in the use of the hypothetical imperatives that only gives proper means to reach ends. Practical reason only guarantees that if you have an end (even a bad end as for example to kill Socrates) you will have to use the proper means to use this end (giving him hemlock, for example, and not water). Practical pure reason, instead, is different, practical pure reason gives us the categorical imperative and for Kant the categorical imperative is good in itself, meaning if people act respecting the categorical imperative, they will be acting morally and universal good will follow. The categorical imperative would never prescribe, for example, the death of Socrates. The use of practical pure reason would never lead us to evil acts, it will always lead us to reach what is right and universally good, even if it is not good for the agent. In doing this Kant can then offer a point of view that establishes a hierarchy in our reason. The existence of a practical pure reason, even with all the efforts made by Kant to prove at least its possibility, can be easily questioned. It is paramount to agree, however, that the argument that Kant offers for the categorical imperative has a strong logical base: if I want something for everybody and I am a part of "everybody" then I have to want this for me as well (if $a$ wants $\mathrm{z}$ for $\mathrm{Vx}$ and a $\mathrm{E} \mathrm{x}$ then $a$ should want $\mathrm{z}$ for $a$ as well). In other words, if I recognise that everyone should stop at a red light and I am part of this "everyone", then I should also stop at a red light because if I don't I would be performing a contradiction, a practical contradiction ${ }^{21}$ as I would be willing for me something that I don't want for everyone, even being part of everyone and this would be clearly irrational. Kant recognises that people do this all the time, but he shows that this is irrational, and so, wrong.

Now it is possible to see how we can use Kant to offer a solution for the dualism. If extreme pain is universally rejected and I am someone who is part of the set "universe", I should also reject pain and I shouldn't inflict extreme pain on others, even if by doing this it has a small cost for me. Inspired by Kant we can argue that the pure egoist would be acting irrationally as 
he refuses to sacrifice even a minimal part of his welfare for the benefit of others. Inspired by Kant we could say that pure egoism is irrational and so it is wrong.

The problem here is that I suspect that Sidgwick would still ponder that the pure egoist has reasons to reject universalism. The pure egoist could still say that he rejects seeing himself as part of "a whole", and because he is only concerned with his existence in the sense that he is not concerned with the existence of anyone else, he can ignore the practical contradiction that he is in, and claim that he is allowed to do what he doesn't want everyone else to do. I cannot see, however, that to do this could still be considered to act rationally. If everyone adopts this point of view, reason would collapse and rules will never work again. If everyone thinks that everybody should respect the red light except themselves, everyone would disrespect red lights and so red lights wouldn't make sense anymore and the confusion and accidents that would ensue on the roads would be the right metaphor for the disarray of such a society. Morally speaking if everyone makes in their own favour an exception in the universality of duty, this would be the end of the idea of duty and this would throw civilisation into a chaos, a practical chaos much worse than the moral scepticism that Sidgwick foresaw.

\section{2- $\quad$ A utilitarianist argument}

Imagine that we are living in the year $2030^{22}$ and a company has built a car that has never been seen before. It is made of a newly discovered wonder material that is resistant to fire and high temperatures and is able to easily move on any roads, a car that can also float over water and even fly. The car is cheaply built and can be sold for a very reasonable amount of money, similar to what is now in our time the cost of a very cheap mobile phone, but it is done in a way that matches the genetic material of the owner and therefore it is only the owner who can use and drive it, it is a bespoke car and cannot be replaced, it should last until your death and would literally die with you.

When the car was initially sold in 2025 it becomes so popular that by now (2030) virtually $100 \%$ of the world's population has one. When the car was initially launched people were informed that the only fuel that could be used to move this amazing machine was a gas (killonious) that accumulates in the atmosphere forever, but it was then said that killonius was completely harmless. However the scientists discovered at the end of 2029 that the killonious gas had terrible long term hidden side effects, and on $1^{\text {st }}$ January 2030 scientists made the announcement that the gas wouldn't affect anyone for the next 1000 years (up to the year 3030) but after this point on the harmful effects would start to be felt in such an increasing and dramatic way that in a thousand and five years, by 3035, it would kill everything and would 
make impossible the existence of any life on earth. The bad news, said the scientists, is that it was confirmed without doubt that the killonius gas accumulates in the atmosphere in a way that it is impossible to remove and revert it, once it is there, it is there forever. But the good news is that if $50 \%$ of the people who owned the car in 2030 stop using it and return it to the factory to be destroyed by the end of the year, the doomsday that was $100 \%$ certain to happen in 3035 would be averted.

Given the gravity of the situation governments of the 20 most richest countries of the world and the online mega companies, together with the 20 most richest men (the trillionaires that by 2030 are part of this new international decisory board that in 2027 replaced the old United Nations and gained the right to make all the international decisions, in the new world order based on free market and total absence of international regulations) decided that based on "considerations of freedom" they wouldn't make any regulations, and in order to avoid putting "pressure" on people, they wouldn't release the data of how many cars would be returned, but that they would expect that people would volunteer to give their cars back. In order to show good will they even agree that people who give their cars back will have a full refund guaranteed including a small compensation, but nothing more than this, in order to avoid the bankruptcy of the innovative company who produced the car. Scientist announced that after the warning and recall launched in 2030 the world would have exactly 1 year to reduce the use of the car to $50 \%$. If half of the population doesn't abandon the use of the car by midnight of $1^{\text {st }}$ January 2031 , life on earth would be condemned for ever from the $1^{\text {st }}$ January of 3031 , with a total extinction to happen by 3035 .

Faced with this situation I doubt that more than half of the population would be willing to make the sacrifice and abandon their cars, condemning then life on earth and sealing our fate. The consequences of selfish attitudes, in this case, would not only be the end of civilization as we know it, but also the end of life ,one of the rarest things in the universe, on one of the rarest planets where it can exist, within 1005 years, a very short period of time, cosmologically speaking. Certainly, the consequences of this attitude would be tragic and no utilitarianist could accept this. If we want to reach the utilitarianist ideal of the greatest happiness for the greatest number it certainly wouldn't be achieved with the end of all life on earth, as the existence of life is the necessary condition of happiness and without life there can be no happiness.

But would it still be rational to abstain to make this sacrifice? According to Sidgwick I suspect that it would, as again, we the human race, are concerned with our own wellbeing in a way that we are not concerned with the welfare of others and so why would we be concerned with the welfare of future generations that we will never know and why should we be willing 
to make sacrifices for them? If egoism as defined by Sidgwick is a method where the rational agent regards quantity of pleasure and pain to himself as alone important in choosing between alternatives of action and seeks always his Greatest happiness ${ }^{23}$ why on earth would we be worried with something that will happen in thousand years? A pure or quantitative egoist (using Sidgwick's terminology) ${ }^{24}$ wouldn't be worried with the future of the planet and would continue using his/her car and the result of this attitude, as per the example, would be the doomsday in 3035. It seems that this choice is still rational for Sidgwick, since everyone who makes this decision is being a pure egoist (where egoism is a legitimate method of ethic) but the result that we have arrived to above is so important and shocking that it is now time to take a deep breath and reflect on this (....).

(...) On reflexion, isn't there something wrong here? Wouldn't this idea of rationality threaten civilisation, life and even the very existence of reason, as without life there is not only no happiness but no rationality anymore? We all know that reason can destroy reason, but is a reason that destroys itself and destroy all life (which is the one necessary condition for the existence of any egoism) still reason? If pure egoism puts reason and life on earth in this position, wouldn't pure egoism be self-defeating? If that is the case, beyond Sidgwick, shouldn't we set a limit to pure egoism?

Selfishness and the dual source view

How much are people willing to sacrifice their own wellbeing today for the sake of others tomorrow is unknown, but if we judge by the existential situation of humankind now, I suspect that the availability even for small sacrifices is far from being what we need to avoid the extinction of life on earth. The doomsday clock was set in 2018 at two minutes to midnight, and this remains the same in 2019. The Bulletin of the Atomic Scientists Science and Security Board warn that we are now in 'a new abnormal', the closest it has ever been to apocalypse. They say:

Humanity now faces two simultaneous existential threats, either of which would be cause for extreme concern and immediate attention. These major threats-nuclear weapons and climate change - were exacerbated this past year by the increased use of information warfare to undermine democracy around the world, amplifying risk from these and other threats and putting the future of civilization in extraordinary danger ${ }^{25}$.

But what has the existential situation of humankind to do with egoism? Probably everything. If we consider climate change, for example, in order to revert the situation some sacrifices are needed. People and countries need to diminish their carbon footprint (the amount 
of carbon dioxide released into the atmosphere as a result of the activities of a particular individual, organisation, or community), but who is willing to change? Who is willing to consume less meat, to use alternative fuels, to reduce the use of private cars? Most of us agree that all this is contributing for climate change and the destruction of environment, but who is actually making the sacrifices? There are, for example, very simple things that everyone could do related to the single use of plastic in order to protect the environment. People could, for example, abstain from acting in an egoistic way, by not throwing plastic into open areas (streets, fields, beaches) and this alone would bring an enormous benefit for the environment, and if we all do this (people and corporations) the problem of plastic pollution would drastically diminish. The reality is, however, that many people are not doing this and the proof is that the problem of plastics in the environment around the world continues and is a huge environmental problem.

The case of plastic bottles is very similar to what Crisp said in the door case 2, as what is at stake here is exactly a greater good to humankind i.e., to preserve the environment, against an insignificant 'cost' (if we even can call this a cost) that is to refrain to throw away plastics in the open. The example of plastic bottles fits perfectly with what Crisp calls the small costs principle in his dual source view, and we could say that pure egoism is clearly mistaken here.

It could still be asked how we establish that a cost is small, and as I have said, this would still depend on the personal circumstances of the person, but in general, if the person is able to understand that there are agent neutral reasons (something that in principle all rational being are capable of) she/he would be able to weight up the agent neutral reasons against her agent relative reasons and conclude in the absolute majority of cases that she should not throw plastic away in order to preserve the greatest good, to keep our oceans and environment plastic-free, avoiding harm to our planet.

I think that Crisp's solution is obvious and perfect for those who are willing to listen and hear the voice of universality and balance agent relative reasons and agent neutral reasons. But how do we deal with the pure egoists who are refusing to do this? How do we deal with the majority of people who continue to throw and leave plastics everywhere? How do we convince the few people that would choose to inflict an excruciating pain on another person in order to avoid a imperceptible pain to themselves and how do we convince the many people that would still choose to keep their "magic car" even to the cost of life on earth being extinct in a thousand and five years? Sidgwick would say that if an egoist remains impervious the only way of rationally inducing him to aim at the happiness of all, is to show him that his own greatest happiness can be best attained by so doing, but the examples given here are exactly examples that show that this coincidence between our happiness and the general happiness doesn't always 
exist, and if this is the case, what do we do? How do we solve the problem of the dualism of practical reason in the very cases where the egoist is a pure egoist who refuses to listen to the voice of the point of view of the universe?

I have no doubt that this is the big ethical puzzle of humankind, whose solution is of paramount importance for the future of life on earth. I strongly suspect that the solution to this problem is not that the great happiness of the egoist can be reached aiming at the happiness of all, because this is simply not always true, the conflict will always exist, as the very existence of the dualism shows. The solution to this problem, I believe, contrarily to Sidgwick, but in line with deontology and utilitarianism, is to show that there is a limit to accept egoism, and even though it is rational for people to listen to agent relative reasons in their deliberations, it is not rational anymore to do this in a way that impairs them to listen to universal reasons. As can be seen through the Kantian and the utilitarianist inspired arguments, that I discussed above, pure egoism could be irrational and could destroy life on earth and if that is the case we could not say that the method is as rational as the two competing methods (intuitionism/deontology and utilitarianism) and we could not say that pure egoism as a method of ethics should be unrestrictedly accepted. Pure egoism when it threatens rationality, human civilisation and even life on earth is self-defeating for humankind, it is self-defeating for our species, and cannot be seen as a legitimate method of ethics anymore.

\section{Concluding remarks}

When Sidgwick pointed to the dualism of practical reason as being the profoundest problem of ethics, he left us, the so-called philosophers of the future, with a task: to dig around in this problem to find a solution that he himself couldn't find. Many of us decided to follow his steps, we are still digging and some things were found in this process. The first thing I found was the confirmation that Sidgwick was right and that deontology/intuitionism and utilitarianism can be reconciled, showing contrarily to what some other excavators found ${ }^{26}$ that the real conflict is not between utilitarians and deontological views, but between the utilitarian and deontological views on one side, the side of altruism or , if we prefer, the side of the point of view of the universe ${ }^{27}$ and pure egoism on the other side. The second thing I found was that the problem of egoism and altruism is not only the profoundest problem of ethics, as Sidgwick pointed out, but one of the most serious ever for humankind as well, and the battle of egoism and altruism, if won by egoism, could lead to the end of civilization as we know it, and to the end of all life on earth. 
As for the solution to the problem, I found that Crisp is the one who got the closest to it, providing a partial solution with his dual source view and the small costs principle showing that we have to balance agent relative and agent neutral reason in a kind of a rational 'negotiation' between both, a rational negotiation between our egoistic and our altruistic motivations. The reason I think that Crisp's solution doesn't solve completely the dualism of practical reason problem is because I suspect that Sidgwick would still say that the pure egoist has reasons not to compromise, and if that is the case he still would have reasons to refuse to accept the small sacrifices that are required by the small costs principle. Considering that in Sidgwick's view egoism as a method of ethics is as legitimate as the other two, it seems to me that this would also be his view on Crisp's solution. Crisp's solution would stand, however, if at this point we go beyond Sidgwick (but back to his two main masters) and we show that to refuse to accept the small cost principle is not rational anymore; that it is not rational to refuse to accept that the universal point of view has, at least, to be accepted as a tie-breaker. Now it would be possible to give a reason why, as Crisp said, in the example of both doors 1 and 2, egoism is mistaken if it means accepting that it would be okay for anyone of us not to be willing to make the small sacrifice of suffering an almost imperceptible pain in order to avoid an excruciant pain to a stranger. Egoism is mistaken in this case, and in many others, because the refusal to take into consideration the agent-neutral reason in this situation and in many others is irrational, and I think that if this is shown the solution given by Crisp would be complete.

There is, as Sidgwick and Crisp pointed out, agent-relative reasons, and they should be considered when we act, but differently to what Sidgwick thought, there is a limit for their acceptance. In agreeing with Kant that the pure egoist would be acting irrationally when he refuses to sacrifice even a minimal part of his welfare for the benefit of others, and in agreeing with utilitarianism that the refusal to do small personal sacrifices in order to obtain great benefits for humankind, once done by each one of us, could lead to the end of civilisation and to the end of life on earth, I hope that I have contributed to show here that the acceptance of the method of egoism in ethics shouldn't be unconditional.

But there are still two questions remaining. The first is related to an observation by Crisp where he says "The dilemma of practical reason it is not quite what Sidgwick took it to be. It arises most starkly in those cases where I can produce a great increase in overall good at a great cost to myself ${ }^{\prime 28}$ Crisp is right that if the small costs principle works, and when I can promote a very great good at a very small cost to myself, other things being equal, my strongest reason overall is to make the sacrifice, this dilemma is solved and the real dilemma is not this one anymore, but another one emerges. The dilemma that emerges is the one where the great overall 
benefit is produced not by a small cost to ourselves, but at a bigger cost to ourselves. In this case it is impossible to say how the agent-relative and the agent-neutral reasons must be balanced, and the dualism shows his true and challenging face. Philosophy has long established that supererogatory acts are praiseworthy, but are beyond duty and cannot be exacted from anyone, and being so I see that the only solution for the dualism, so rewritten, is to rely on heroes, that History shows that fortunately have always existed and we believe will always exist. If, touch wood, fate puts the survival of our civilisation at risk and the only way that humankind can survive is if one of us makes the ultimate sacrifice, we can only hope that a hero will be there, in the right place at the right time.

Personally I think, however, that we shouldn't be worried with this now. The real problems faced by humankind at the moment don't need heroes to solve them, even though certainly they have everything to do with the dualism of practical reason when it is revisited. When this happens then the discussion about pure egoism and the limits to it have to be put on the table in a different shape, the shape of institutional and collective actions. A company, with their many shareholders can be seen as an collective body, and can act as a pure egoist corporation, aiming exclusively to maximise their profits, refusing to sacrifice some of this profit for the general good, and even incorporating practices that involve bribery and corruption, or can choose act into a more altruistic way, accepting to reduce profits for the good of humankind, being more environmentally friendly, giving better working conditions to employees, being more customer-orientated and being relentless against corruption. In this sense the role of States could also be incorporated in this discussion. A world where "America first" is claimed is a world where similar claims can be made by all the other 200 countries generating a wave of England first, China first, Japan first, Germany first, Iran first, Iraqi first similar claims that could generate a warlike situation among all the States.

Curiously Hobbes, one of the greatest philosophers of egoism, already warned us that a war of all against all (bellum omnium contra omnes) is the one that describes the human existence in a state of nature ${ }^{29}$, and this is an extremely dangerous situation that puts the conservation of life of every human at stake ${ }^{30}$. Hobbes proposed that we should leave the state of nature and ingress in the state of civilisation exactly because he perceived that pure egoism was self-defeating and we should put limits on this, the limits of civilisation ${ }^{31}$. But are we respecting those limits today? I leave the final answer for the philosophers of the future, as I believe they will be in a better situation to answer this question, but I suspect that globally we are now living in a second order state of nature that threatens civilisation at this moment in 
history, one that is even worse than the state of nature described by Hobbes, because it could put humanity at an unprecedent existential risk $^{32}$.

When we revise the dualism of practical reason, we can conclude that this is in fact the profoundest problem of ethics, a problem so profound and serious that even the survival of humanity is connected to it. Humankind is in a quandary, but there are fair and rational solutions on the table. We cannot continue at the pace we are now, without any limits to egoism either on a personal level or at a corporational and institutional level. The future of civilisation and even the future of all life on earth is at stake. The clock is ticking and it is now two minutes to mid-night. Agent-relative and agent-neutral reasons need to be balanced, and the universal point of view has to be heard, otherwise it could be too late for all of us, including the pure egoists. 


\section{Notes:}

${ }^{1}$ Cinara Nahra is professor of philosophy and ethics at Universidade Federal do Rio Grande do Norte (UFRN), Natal, Rio Grande do Norte (R.N.), Brasil. E-mail: cinaranahra@hotmail.com

* I would like to thank Roger Crisp for all his suggestions and positive input.

** This study was financed in part by the Coordenação de Aperfeiçoamento de Pessoal de Nível Superior Brasil (CAPES/ Print program)

${ }^{2}$ Sidgwick, Henry The Methods of Ethics (London: Mac Millan and Co,1874) $1^{\text {st }}$ ed.

${ }^{3}$ Schultz, B Eye of the Universe : An Intellectual Biography (Cambridge: Cambridge University Press,2004)

${ }^{4}$ Sidgwick, H The Methods of Ethics (USA: Hackett Publishing Company,1907(1981) $7^{\text {th }}$ ed. The expressions self-interest and altruism, interest and duty, my happiness and general happiness appear for example in the preface of the $6^{\text {th }}$ ed. $x$ viiii, self-interest and duty in the preface $x i x$ and in the concluding chapter p.508.

${ }^{5}$ Also in the preface of the $6^{\text {th }}$ edition of The Methods (xvi) E.E Constance Jones writes: "There is one further matter of importance. Among the MS. material which Professor Sidgwick intended to be referred to, in preparing this edition for the press, there occurs, as part of the MS. notes for a lecture, a brief history of the development in his thought of the ethical view which he has set forth in the Methods of Ethics. This, though not in a finished condition, is in essentials complete and coherent, and since it cannot fail to have peculiar value and interest for students of the book, it has been decided to insert it here. Such an arrangement seems to a certain extent in harmony with the author's own procedure in the Preface to the Second Edition; and in this way while future students of the Methods will have access to an introductory account which both ethically and historically is of very exceptional interest, no dislocation of the text will be involved. In the account referred to Professor Sidgwick says:--- "My first adhesion to a definite Ethical system was to the Utilitarianism of Mill: I found in this relief from the apparently external and arbitrary pressure of moral rules which I had been educated to obey, and which presented themselves to me as to some extent doubtful and confused; and sometimes, even when clear, as merely dogmatic, unreasoned, incoherent. My antagonism to this was intensified by the study of Whewell's Elements of Morality which was prescribed for the study of undergraduates in Trinity. It was from that book that I derived the impression which long remained uneffaced---that Intuitional moralists were hopelessly loose (as compared to mathematicians) in their definitions and axioms. The two elements of Mill's view which I am accustomed to distinguish as Psychological Hedonism [that each man does seek his own Happiness] and Ethical Hedonism [that each man ought to seek the general Happiness] both attracted me, and I did not at first perceive their incoherence. Psychological Hedonism---the law of universal pleasure-seeking---attracted me by its frank naturalness. Ethical Hedonism, as expounded by Mill, was morally inspiring by its dictate of readiness for absolute self-sacrifice. They appealed to different elements of my nature, but they brought these into apparent harmony: they both used the same words "pleasure", "happiness", and the persuasiveness of Mill's exposition veiled for a time the profound discrepancy between the natural end of action---private happiness, and the end of duty---general happiness. Or if a doubt assailed me as to the coincidence of private and general happiness, I was inclined to hold that it ought to be cast to the winds by a generous resolution. But a sense grew upon me that this method of dealing with the conflict between Interest and Duty, though perhaps proper for practice could not be final for philosophy".

${ }^{6}$ See Sidgwick, Henry 1874 The Methods of Ethics (London: Mac Millan and Co,1874) $1^{\text {st }}$ ed. Sidgwick clarifies (book 1,ch.1, introduction, p.9): "There remain the two systems which make Happiness an ultimate end. Both of these are frequently called Utilitarianism. We may distinguish them as Egoistic and Universalistic Hedonism: as it is the latter of these, as taught by Bentham and his successors, that has become famous as Utilitarianism, I shall always restrict that term to this signification. For Egoistic Hedonism it is somewhat hard to find a single perfectly appropriate term. I shall often call this simply Egoism but it may sometimes be convenient to call it Epicureanism : for though this name more properly denotes a particular historical system it has come to be commonly used in the wider sense in which I wish to employ it".

\footnotetext{
${ }^{7}$ Sidgwick, H The Methods of Ethics (USA: Hackett Publishing Company,1907(1981)) $7^{\text {th }}$ ed. Preface to the $6^{\text {th }}$ ed $x x i$

${ }^{8}$ Phillips, David Sidgwickian Ethics (Oxford: Oxford University Press,2011) p.150.
}

${ }^{9}$ Sidgwick, H ME (1907) p. 508. 
${ }^{10}$ Crisp, Roger “The Dualism of Practical Reason” p.53, Proceedings of the Aristotelian Society, vol. 96 (1996): 53-73. In Crisp, Roger Reasons and the Good (Oxford: Oxford University Press,2006) p. 135 he clarifies that his version is in a significant way different from, and hence less pessimistic than Sidgwick's.

${ }^{11}$ Crisp, R The Cosmos of Duty: Henry Sidgwick's Methods of Ethics (Oxford: Oxford University Press, 2015) p. 231

${ }^{12}$ Crisp, R “The Dualism of Practical Reason” p.53

${ }^{13}$ Crisp, R The Cosmos of Duty p.231

${ }^{14}$ Crisp, R Reasons and the Good p. 132

15 Ibid., p.132

${ }^{16}$ Ibid., p. 134

${ }^{17}$ Ibid., p. 140

${ }^{18}$ Sidgwick, H ME (1907) p.498

${ }^{19}$ Ibid., p.498

${ }^{20}$ Kant, I Critique of Practical Reason (Indianapolis/Cambridge: Hackett Publishing Company, [1788] 2002) KpV 58 p.78 The sole objects of a practical reason are, therefore, those of the good and the evil. For by the first one means a necessary object of our power of desire, by the second, of our power of loathing but both according to a principle of reason. Further $(\mathrm{KpV} 108)$ Kant writes that "As pure practical reason it seeks for the practically conditioned (which rests on inclinations and natural need) likewise the unconditioned; moreover, it does not seek this unconditioned as determining basis of the will, but, even when this determining basis has been given (in the moral law), it seeks the unconditioned totality of the object of pure practical reason, under the name of the highest good.

21 See Kant, Immanuel Groundwork for the Metaphysics of Morals (New Haven and London: Yale University Press, [1785] 2002) trad. Allen Wood (GMS AA 04:425) p. 42. There Kant writes: "Now if we attend to ourselves in every transgression of a duty, then we find that we do not actually will that our maxim should become a universal law, for that is impossible for us, but rather will that its opposite should remain a law generally; yet we take the liberty of making an exception for ourselves, or (even only for this once) for the advantage of our inclination. Consequently, if we weighed everything from one and the same point of view, namely that of reason, then we would encounter a contradiction in our own will, namely that objectively a certain principle should be necessary as a universal law and yet subjectively that it should not be universally valid, but rather that it should admit of exceptions. But since we consider our action at one time from a point of view that accords entirely with reason, and then, however, also the same action from the point of view of a will affected by inclination, there is actually no contradiction here, but only a resistance of inclination against the precept of reason (antagonismus), through which the universality of the principle (universalitas) is transformed into a mere general validity (generalitas), so that the practical principle of reason is supposed to meet the maxim halfway". This passage suggests that Kant had already his version of the dualism of practical reason, previously to Sidgwick. Kant solution, however is entirely different from Sidgwick. According to Kant there is no contradiction when we recognise the universal law but we don't act according to the universal law, because our will is affected by reason(pure reason) and by empirical inclinations and so there is a kind of "war" between these two influences in our will, generating then a conflict and a resistence of inclination against reason. The contradiction would exist if we see everything from the point of view of pure reason, that Kant recognises it is not the case since we are human beings and we don't have a saint will. The Kantian solution is that as human beings we should always allow the pure practical reason to win the battle, and so doing we will be acting morally. Kant wouldn't accept that the exception that we make for ourselves in the universality of law is rational, on the contrary, it is the proof that many times inclination wins the battle and we transgress our duty.

${ }^{22}$ The choice of the year 2030 in this example is to remember the 2030 UN Agenda for Sustainable Development and their five critical dimensions: people, prosperity, planet, partnership and peace (available at https://www.unssc.org/sites/unssc.org/files/2030 agenda_for_sustainable development_kcsd_primer_en.pdf See also The IPCC (Intergovernmental Panel on Climate Change) 2018 rapport available at file:///H:/My $\% 20$ documents $\% 202019 \% 20 \mathrm{HP} \% 20$ computer/environment $\% 20 \mathrm{ipcc} \% 20$ rapport.pdf stating that 
"Human activities are estimated to have caused approximately $1.0^{\circ} \mathrm{C}$ of global warming above pre-industrial levels, with a likely range of $0.8^{\circ} \mathrm{C}$ to $1.2^{\circ} \mathrm{C}$. Global warming is likely to reach $1.5^{\circ} \mathrm{C}$ between 2030 and 2052 if it continues to increase at the current rate.

${ }^{23}$ Sidgwick $M E$ (1907) p.95

${ }^{24}$ Ibid,p.95

${ }^{25}$ See Bulletin of the atomic scientists at https://thebulletin.org/doomsday-clock/current-time/

The Bulletin was founded in 1945 by Manhattan Project scientists and today is an independent, non-profit organisation that accesses scientific advancements involving both benefits and risks to humanity, with the goal of influencing public policy to protect our planet and all its inhabitants.

26 Skorupski, John "Three Methods and a Dualism" Proceedings of the British Academy v. 109 (2001): 61-81. In this article Skorupski concludes, contrarily to Sidgwick, that there is no dualism of practical reason. Pure practical reason says that the good is agent-neutrality, but if Sidgwick is talking about practical reason in general then there are many dualisms, not only two.

${ }^{27}$ On the point of view of the universe see, for example, Lazari-Radek, Katarzyna de and Singer, P. The Point of View of the Universe: Sidgwick and Contemporary Ethics (Oxford: Oxford University Press, 2014)

${ }^{28}$ Crisp, Roger "The Dualism of Practical Reason” p.65

${ }^{29}$ See Hobbes, T Leviathan (Oxford: Oxford University Press, [1651] 1996) and Hobbes, T De Cive, The latin version (Oxford: Clarendon Press, [1647] 1983) ed.by Howard Warrender.

${ }^{30}$ It is important to notice that Sidgwick (1907) ME, 1, VII, p.89 calls attention to the fact that " the term "egoistic" is ordinarily and not improperly applied to the basis on which Hobbes attempted to construct morality; and on which alone, as he held, the social order could firmly rest, and escape the storms and convulsions with which it seemed to be menaced from the vagaries of the unenlightened conscience. But it is not strictly the end of Egoism as I have defined it---greatest attainable pleasure for the individual---but rather "self-preservation", which determines the first of those precepts of rational egoism which Hobbes calls "Laws of Nature", viz., "Seek peace and ensue it". And in the development of his system we often find that it is Preservation rather than Pleasure, or perhaps a compromise between the two, that is taken as the ultimate end and standard of right conduct".

${ }^{31}$ Nothing apprehends more the Hobbesian spirit than the poem of Henricus Bruno that appears in the second edition of De Cive, op cit. "Nature makes man, the state makes citizens: and every man this mortal life can live. Yet though who wouldst a living life enjoy. Learn civilly to live as Thomas bids. So shalt thou dwell, within this world, no fool. Nor yet degenerate, no cypher mere Nor one that's born but to destroy its fruits. And so, with me thou'l say, if right it be to measure man both by the name and praise. They've won theirselves and by their genious too. If Virtue yet unmeasured can be held. By place and space, although with fame it flies. And spreads from east to west where dwells the sun. Hobbes with his Britons, sundered from the world, Citizen alike of that whole world shall be".

${ }^{32}$ On existential risks see for example Bostrom, Nick "Existential Risks: Analyzing Human Extinction Scenarios and Related Hazards" Journal of Evolution and Technology v.9 (2002) p.1-31 


\section{References:}

Bostrom, Nick 2002 "Existential Risks: Analysing Human Extinction Scenarios and Related Hazards" Journal of Evolution and Technology v.9 (2002)

Crisp, Roger (1996) “The Dualism of Practical Reason” p.53, Proceedings of the Aristotelian Society, vol. 96

Crisp, Roger Reasons and the Good 2006 (Oxford: Oxford University Press,2006)

Crisp, Roger 2015 The Cosmos of Duty: Henry Sidgwick's Methods of Ethics (Oxford: Oxford University Press, 2015)

Hobbes, Thomas Leviathan [1651] 1996 (Oxford: Oxford University Press, 1996)

Hobbes, Thomas De Cive, The latin version [1647] 1983 (Oxford: Clarendon Press, 1983) ed.H. Warrender

Kant, I Critique of Practical Reason [1788] 2002 (Indianapolis/Cambridge: Hackett Publishing Company, 2002)

Kant, Immanuel Groundwork for the Metaphysics of Morals [1785] 2002 (New Haven and London: Yale University Press, 2002)

Lazari-Radek, Katarzyna de and Singer, Peter 2014 The Point of View of the Universe: Sidgwick and Contemporary Ethics (Oxford: Oxford University Press, 2014)

Phillips, David 2011 Sidgwickian Ethics (Oxford: Oxford University Press,2011)

Schultz, B 2004 Eye of the Universe: An Intellectual Biography (Cambridge: Cambridge University Press,2004)

Sidgwick, Henry 1874 The Methods of Ethics (London: Mac Millan and Co,1874) $1^{\text {st }}$ ed.

Sidgwick, Henry The Methods of Ethics [1907] (1981) (USA: Hackett Publishing Company, 1981) $7^{\text {th }}$ ed

Skorupski, John 2001 “Three Methods and a Dualism” Proceedings of the British Academy v. 109 (2001)

Bulletin of the atomic scientists available at https://thebulletin.org/doomsday-clock/current-time/

United Nation 2030 UN Agenda for Sustainable Development (available at https://www.unssc.org/sites/unssc.org/files/2030 agenda for sustainable development kcsd prim er en.pdf 
IPCC (Intergovernmental Panel on Climate Change) 2018 rapport available at

file:///H:/My\%20documents $\% 202019 \% 20 \mathrm{HP} \% 20$ computer/environment $\% 20 \mathrm{ipcc} \% 20$ rapport.pdf 